Journal of Applied Pharmaceutical Science Vol. 2 (10), pp. 099-103, October, 2012

Available online at http://www.japsonline.com

DOI: $10.7324 /$ JAPS.2012.21020

ISSN 2231-3354 (cc) BY-NC-SA

\title{
Antibacterial and antifungal activities of Actinobacteria isolated from Rathnagiri hills
}

\author{
S. Silambarasan ${ }^{1}$, E. Praveen kumar ${ }^{1}$, T. Murugan $^{2}$, D. Saravanan ${ }^{1}$ and R. Balagurunathan ${ }^{3 *}$ \\ ${ }^{1}$ Department of Microbiology, Sri Sankara Arts \& Science College, Kanchipuram - 631 561, Tamil Nadu, India \\ ${ }^{2}$ Kamini Research Foundation, Thuckalay - 629175, Tamil Nadu, India \\ ${ }^{3}$ Department of Microbiology, Periyar University, Salem - 600 011, Tamil Nadu, India
}

\section{ARTICLE INFO}

Article history:

Received on: 18/08/2012

Revised on: 29/08/2012

Accepted on: 05/09/2012

Available online: 29/10/2012

Key words:

Antinomycetes,

Secondary metabolites,

Antimicrobial activity,

Streptomyces sp.

\begin{abstract}
This study was performed to isolate actinomycete colonies having antibacterial and antifungal activity from soil samples. A total of 27 actinomycete colonies were isolated in pure culture from five soil samples using Starch casein agar medium. Entire isolates were screened for their antimicrobial activity by agar plug method against five each of human pathogenic bacteria and fungi. Of this, 7 strains inhibits $B$. substilis, 3 strains inhibits Klebseilla sp, 6 strains inhibits B. cerus, 5 strains inhibits $S$. aureus and only 2 strains inhibits $E$. coli. Incase of fungi all the actinobateria has moderate activity with less fungal strains, only 1 strain (RA 5) inhibits entire fungus except Penicillium sp. The metabolites from potent strain was produced by fermentation, separated by centrifugation, it was tested for their antimicrobial activity against the test bacterial and fungal strains by well diffusion and disc diffusion method. In this study, the metabolites from RA5 (identified as Streptomyces sp.) have showed good antibacterial and antifungal activity. Since many isolates showed inhibitory activity against indicator bacteria, it is suggestive that Rathnagiri hill's soil could be an interesting source to explore for antibacterial secondary metabolites.
\end{abstract}

\section{INTRODUCTION}

Actinomycetes are diverse group of Gram positive bacteria that usually grow by filament formation. They belong to the order Actinomycetales (Superkingdom: Bacteria, Phylum: Firmicutes, Class: Actinobacteria, Subclass: Actinobacteridae) (Okami and Hotta 1988). They are free living, saprophytic bacteria and a major source for the production of antibiotics (Atta et al., 2009), widely distributed in natural and manmade environments and play an important role in the degradation of organic matter (Sateesh $e t$ al., 2011). They are the most economically and biotechnologically valuable prokaryotes able to produce wide range of bioactive secondary metabolites, such as antibiotics, antitumor agents, immunosuppressive agents, enzymes (Ravikumar et al., 2011), cosmetics, vitamins, nutritional materials, herbicides, pesticides

\footnotetext{
* Corresponding Author
}

R. Balagurunathan,

Department of Microbiology, Periyar University,

Salem - 600 011, Tamil Nadu, India.

Tel: 9443446325
(Ogunmwonyi et al., 2010) and also well known as a rich source of antibiotics and bioactive molecules (Sateesh et al., 2011). Around 23000 bioactive secondary metabolites by microorganisms have been reported and over 10000 of these compounds are produced by Actinomycetes (Vimal et al., 2009). Among these around 7600 compounds are produced by Streptomyces species. Many of these secondary metabolites are potent antibiotics, which has made Streptomycetes the primary antibiotic-producing organisms exploited by the pharmaceutical industry (Jensen et al., 2007).The genus Streptomyces has long been recognized as a rich source of useful secondary metabolites and continues to be a major source of new bioactive molecules (Miyadoh 1993). As the frequency of novel bioactive compounds discovered from terrestrial actinomycetes decreases with time, much attention has been focused on screening of actinomycetes from diverse environments (Thenmozhi et al., 2011). They have been looked upon as a potential source of antibiotic and the past experience proves that actinomycetes are the richest source of secondary metabolites 
(Ashadevi, 2005). In the present investigation an effort was made to screen antagonistic terrestrial actinomycetes from soil of Rathnagiri hills, Tamil Nadu, India which is largely unscreened ecosystem for the isolation of potent antibiotic producing actinomycets.

\section{MATERIALS AND METHODS}

\section{Sample collection and isolation}

A total of five soil samples (4-5g for each) were collected from different sites of Rathnagiri hill forest, Vellore district, Tamilnadu at a depth of $4-5 \mathrm{~cm}$ from surfaces. All the samples were pre-treated by heating at $55^{\circ} \mathrm{C}$ for $10 \mathrm{~min}$ to minimize the bacterial contamination. $1 \mathrm{~g}$ of each sample was suspended in $10 \mathrm{ml}$ of sterile distilled water and mixed properly. Serial dilutions were done up to $10^{-5}$ using sterile distilled water and agitated with the vortex at maximum speed. An aliquot of $0.1 \mathrm{ml}$ of each dilution from $10^{-2}$ to $10^{-5}$ was taken and spread evenly over the surface of starch casein agar (SCA) plates sing glass L-rod. Plates were incubated at $28^{\circ} \mathrm{C}$ for 5 - 7days (Narendra Kumar et al., 2010). After incubation, the individual actinobacterial colonies were picked out and subcultured into freshly prepared yeast extract malt extract agar (ISP2) agar plates. Then the pure colonies were maintained in yeast extract malt extract agar slant and kept at $4^{\circ} \mathrm{C}$ until further use.

\section{Screening of actinobacteria for antagonistic activity}

18 hrs broth cultures of test bacterial strains (Staphylococcus aureus, Bacillus subtilis, Bacillus cereus, Klebsiella sp and Escherichia coli), 72 hrs broth cultures of fungal strains (Fusarium sp, Curvularia sp, Penicillium sp, Candida abicans and Candida trophicalis) were swabbed individually into freshly prepared nutrient agar (NA) and Sabouraud's dextrose agar (SDA) plates respectively. (All the test strains were obtained from department of Micobiology, Sri Sankara Arts and Science College, Kanchipuram).

Antagonistic activity of actinobacterial isolates were tested by adopting agar plug method. Agar plug were removed with a $5 \mathrm{~mm}$ diameter core from 10 days grown cultures of the actinobacteria from ISP2 agar medium. The surface growth on agar was removed with sterile knife to obtain only the diffused microbial metabolites in the agar plugs. The agar plugs were placed onto the nutrient agar plate which was previously swabbed with the test bacterial and fungal pathogens. The plates containing bacterial strains were incubated at $37^{\circ} \mathrm{C}$ for $24 \mathrm{hrs}$ and the plates containing fungal strains were incubated at room temperature for 5 days. Following incubation, antimicrobial activity was indicated by the formation of an inhibition zone which may provided an indication of diffused antimicrobial metabolites produced by the growing actinobacterial culture (Mohanraj et al., 2011).

\section{Production of bioactive compounds}

Based on the preliminary screening, the antagonistic natures of actinobacteria were conformed and it was further studied by shake flask fermentation technique. The potential strains were inoculated in $50 \mathrm{ml}$ of freshly prepared sterile yeast extract malt extract broth medium (ISP2) in a $250 \mathrm{ml}$ conical flask. The flasks were placed on shaker at $120 \mathrm{rpm}$ for 7-8 days. After incubation, the cells free supernatant was separated by centrifugation at $10000 \mathrm{rpm}$ for 10 minutes and compound (Radhakrishnan et al., 2007).

\section{Testing of antimicrobial activity - well diffusion method}

The test bacterial and fungal cultures as mentioned in preliminary screening were inoculated into freshly prepared NA plates (bacterial strains) and SDA plates (fungal strains) using sterile cotton swabs. Then the wells were made (about $5 \mathrm{~mm}$ in dia) on the all inoculated plates using well cutter and each well was loaded with $100 \mu \mathrm{l}$ of cell free culture supernatant. The plates containing bacterial strains were incubated at $37^{\circ} \mathrm{C}$ for $24 \mathrm{hrs}$ and the plates containing fungal strains were incubated at room temperature for 4-5 days. After incubation, the zone of inhibition was measured and expressed as millimeter in diameter (Mohanraj et al., 2011).

\section{Testing of antimicrobial activity - Disc diffusion method}

The cell free supernatant which showed maximum zone of inhibition in well diffusion assay was extracted using equal volume of solvents such as ethyl acetate, methanol and chloroform for overnight. Then the solvent portion was collected and concentrated by evaporation (Pazhani Murugan et al., 2010).

The crude extracts of potential strain were screened for antimicrobial activity by disc diffusion method. All the crude extracts were impregnated with sterile filter paper disc at $100 \mu \mathrm{g} / \mathrm{disc}$ concentration and tested against test strains as mentioned in preliminary screening (Mohanraj et al., 2011).

\section{Characterization and identification of potential actinobacteria}

To identify the potential actinobacteria, it was characterized by standard those methods described by Shirling and Gottileb (1996). Cultural morphology, Microscopic appearance, Utilization of carbon, Physiology and biochemical characters was studied. Based on the expressed phenotypic characters, the potential actinobacteria strains were tentatively identified with the help of the actinobase database (Ugawa et al., 1989).

\section{RESULTS AND DISCUSSION}

A total of 27 morphologically different actinobacterial colonies were selected from five soil samples and made pure culture. Entire isolated strains were screened for antagonistic activity against selected bacterial and fungal pathogens. Of this, 7 strains inhibits B. substilis, 3 strains inhibits Klebseilla sp, 6 strains inhibits B. cerus, 5 strains inhibits $S$. aureus and only 2 strains inhibits E. coli (Table 1).

The results revels that most of the active isolates were active against gram positive bacteria (B. subtilis, B. cereus and Staph. aureus) than gram negative bacteria. The reason for 
Table. 1: Screening of actinobacteria for antagonistic activity.

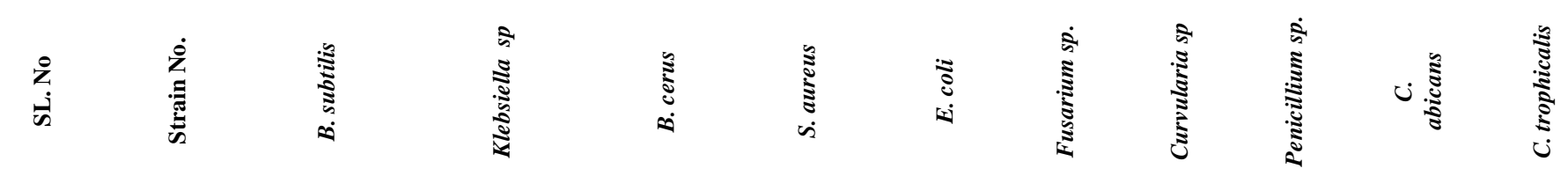

\begin{tabular}{|c|c|c|c|c|c|c|c|c|c|c|c|}
\hline 1 & RA1 & - & 8 & - & - & - & 10 & - & - & - & - \\
\hline 2 & RA2 & - & - & - & - & - & - & - & - & - & - \\
\hline 3 & RA3 & 15 & - & 12 & 13 & - & - & - & - & - & - \\
\hline 4 & RA4 & 10 & - & - & - & - & - & - & - & - & - \\
\hline 5 & RA5 & 15 & 16 & 15 & 14 & 16 & - & 16 & - & 17 & 16 \\
\hline 6 & $\mathrm{RB} 1$ & - & - & - & - & - & - & - & - & - & - \\
\hline 7 & RB2 & - & 8 & 9 & 8 & 10 & 6 & - & 8 & - & - \\
\hline 8 & RB3 & - & - & - & - & - & - & - & - & - & - \\
\hline 9 & RB4 & - & - & - & - & - & - & - & - & - & - \\
\hline 10 & RB5 & - & - & 9 & - & - & - & - & - & - & - \\
\hline 11 & $\mathrm{RC} 1$ & - & - & - & - & - & - & - & - & - & - \\
\hline 12 & $\mathrm{RC} 2$ & - & - & - & - & - & - & - & - & - & - \\
\hline 13 & RC3 & - & - & - & - & - & - & - & - & - & - \\
\hline 14 & RC4 & 8 & - & - & 10 & - & - & - & - & - & - \\
\hline 15 & RC5 & - & - & - & - & - & - & - & - & - & - \\
\hline 16 & RD1 & 11 & - & 12 & - & - & - & - & - & - & - \\
\hline 17 & RD2 & - & - & - & - & - & - & - & - & - & - \\
\hline 18 & RD3 & - & - & - & 8 & - & - & - & - & - & - \\
\hline 19 & RD4 & 9 & - & 8 & - & - & - & - & - & - & - \\
\hline 20 & RD5 & - & - & - & - & - & - & - & - & - & - \\
\hline 21 & RE1 & 9 & - & - & - & - & - & - & - & - & - \\
\hline 22 & RE2 & - & - & - & - & - & - & - & - & - & - \\
\hline 23 & RE3 & - & - & - & - & - & - & - & - & - & - \\
\hline 24 & RE4 & - & - & - & - & - & - & - & - & - & - \\
\hline 25 & RE5 & - & - & - & - & - & - & - & - & - & - \\
\hline 26 & RF1 & - & - & - & - & - & - & - & - & - & - \\
\hline 27 & RF2 & - & - & - & - & - & - & - & - & - & - \\
\hline
\end{tabular}

different sensitivity between gram positive and gram negative bacteria could be ascribed to the morphological differences between these microorganisms, gram negative bacteria having an outer polysaccharide membrane carrying the structural lipopolysaccharide components. This makes the cell wall impermeable to lipophilic solutes, The gram positive should more susceptible having only an outer peptidoglycan layer which is not an effective permeability barrier (Scherrer \&Gerhardt, 1971). Incase of fungi all the actinobateria has moderate activity with less fungus, only 1 strain (RA 5) inhibits entire fungus except Penicillium sp.(Table 1).

In the present study agar plug method was used for the detection of antagonistic activity. This method allowed utilizing very small amount of medium for the culturing and production of bioactive compounds and also for the detection of antimicrobial activity of more number of actinobacterial isolates against wide range of pathogens with less investment costs (Mohanraj et al., 2011)

The potential actinobacteria was selected based on the results in preliminary screening of actinobacteria for antagonistic activity. In that only one actinobacterial strain namely RA5 which inhibit all the five tested bacterial and fungal pathogens, which was selected as potent strain and used for fermentation.

In well diffusion method the crude culture filtrate of actinobacterial strain (RA5) showed good activity against all the tested bacterial strains and fungal strains (Table 2). Actinomycetes are the most biotechnologically valuable prokaryotes responsible for the production of about half of the discovered bioactive secondary metabolites including antibiotics (Yuan et al., 2010). They are the main source of clinically important antibiotics, most of which are too complex to be synthesized by combinatorial chemistry. Thus, microbial natural products still appear as the most promising sources for developing future antibiotics (Deepika Sharma, et al., 2011).

The crude extracts prepared from culture filtrates were analyzed for their antimicrobial activity by disc diffusion method. In this study, the chloroform extract showed good activity against all the test pathogens (Table 2). Isolation of an antibiotic from culture filtrate is largely determined by its chemical nature. Solvent extraction is usually employed for the extraction of antibiotics from the culture filtrates. Organic solvents with different polarities have been used by many researchers for the extraction of antimicrobial compounds from actinomycetes (Selvameenal et al., 2009). This result clearly indicated that the antimicrobial activity of potential strain is due to the production of extracellular bioactive compounds. The published literature stated that most of the antibiotics from actinomycetes are extracellular in nature (Valan arasu et al., 2008)

Under microscopic observation, strain RA5 showed the presence of substrate and aerial mycelium with rectus flexible 
(RF) arrangement of spore chains. Good growth was observed on all the tested medium except ISP6 and ISP7 strain RA5 utilized only few sugars and showed good growth at $\mathrm{pH} 7$ and 9 and temperature of $30^{\circ} \mathrm{C}$ and $40^{\circ} \mathrm{C}$. Based on the micro morphological, cultural and physiological characterization (given in table 3) the potential strain was suspected to be Streptomyces sp. Further chemotaxonomic and molecular characterization is needed to confirm its taxonomic position.

Table. 2: Antimicrobial activity of actinobateria.

\begin{tabular}{lcc}
\hline \multirow{2}{*}{ Test organism } & \multicolumn{2}{c}{ Zone of inhibition (mm in dia.) } \\
\cline { 2 - 3 } & Well diffusion method & Disc diffusion method \\
\hline B.substilus & 13 & 16 \\
Klebsella & 13 & 17 \\
B.cerus & 15 & 19 \\
S.aureus & 14 & 18 \\
E. coli & 15 & 17 \\
Curvularia sp. & 14 & 16 \\
C. albicans & 17 & 19 \\
C. trophicalis & 16 & 18 \\
\hline
\end{tabular}

Table. 3: Characteristics of actinobacterial strain (RA5).

\begin{tabular}{|c|c|}
\hline Charactersitics & Strain RA5 \\
\hline \multicolumn{2}{|l|}{ Carbon compounds } \\
\hline Glucose & + \\
\hline Sucrose & - \\
\hline Xylose & + \\
\hline Inositol & + \\
\hline Mannitol & + \\
\hline Fructose & - \\
\hline Rhamnose & + \\
\hline Raffinose & - \\
\hline Arabinose & - \\
\hline Cellulose & - \\
\hline \multicolumn{2}{|l|}{ Enzyme activities } \\
\hline Amylase & + \\
\hline Lipase & - \\
\hline Protease & + \\
\hline \multicolumn{2}{|l|}{ Temperature tolerance $\left({ }^{\circ} \mathrm{C}\right)$} \\
\hline 20 & Moderate \\
\hline 30 & Good \\
\hline 40 & Good \\
\hline 45 & + \\
\hline \multicolumn{2}{|l|}{ pH Tolerance: } \\
\hline 5 & - \\
\hline 7 & Good \\
\hline 9 & Good \\
\hline 11 & - \\
\hline Anaerobic condition & Moderate \\
\hline
\end{tabular}

'+' presence of growth; '-'absence of growth

\section{CONCLUSION}

Findings of the present study conclude that Rathnagiri hill is the potential ecosystem for antagonistic actinomycetes which deserves for bioprospecting. Considering the mentioned above results, it could be seen that one from the investigated strains (RA5) exhibited higher activity against pathogenic bacteria and fungi. Probably, the antibacterial activity of the strain is due to an antibacterial complex active against pro- and eukaryotic organisms. This actinobacteria (RA5) have a potential to be included in researches of new preparations with antibacterial and antifungal action also for plant protection.

\section{ACKNOWLEDGEMENT}

Authors thank Prof. K.R. Venkatesan, Principal, and the management of Sri Sankara Arts \& Science College, Kanchipuram for providing all the facilities to carry out this project.

\section{REFERENCES}

Ashadevi N.K. Isolation and identification of marine actinomycetes and their potential in antimicrobial activity. Pakistan J. Biological Sciences. 2005; 9(3): 470-472.

Atta H.M., Dabour S.M., Desoukey S.G. Sparsomycin antibiotic production by Streptomyces sp. AZ-NIOFD1: taxonomy, fermentation, purification and biological activities. Am Eurasian J Agric Environ Sci. 2009; 5(3): 368-377.

Deepika Sharma, Talwinder Kaur, Chadha B.S., Rajesh Kumari Manhas. Antimicrobial Activity of Actinomycetes Against Multidrug Resistant Staphylococcus aureus, E. coli and Various Other Pathogens Tropical Journal of Pharmaceutical Research. 2011; 10 (6): 801-808.

Jensen P.R., Williams P.G., Oh D.C., Zeigler L., Fenical W. Species-specific secondary metabolite production in marine actinomycetes of the genus Salinispora. Appl Environ Microbiol. 2007; 73(4): 11461152 .

Miyadoh S. Research on antibiotic screening in Japan over the last decade: a producing microorganisms approach, Actinomycetol. 1993; 7:100-106.

Mohanraj D., Bharathi S., Radhakrishnan M., Balagurunathan R. Bioprospecting of actinobacteria from Yelagiri hills with special reference to antibacterial activity. J. Chem. Pharm. Res. 2011; 3(3):439446.

Narendra Kumar, Ravi Kant Singh, Mishra S.K., Singh A.K., Pachouri U.C. Isolation and screening of soil Actinomycetes as source of antibiotics active against bacteria International Journal of Microbiology Research. 2010; 2 (2):12-16.

Ogunmwonyi I.H., Mazomba N., Mabinya L., Ngwenya E., Green E., Akinpelu D.A., et al. Studies on the culturable marine actinomycetes isolated from the Nahoon beach in the Eastern Cape Province of South Africa. Afr J Microbiol Res. 2010; 4(21): 2223-2230.

Okami Y., Hotta K. Search and discovery of new antibiotics. In: Actinomycetes in biotechnology (Eds. M. Good Fellow, S.T. Williams and M. Mordarski). Academic press, London (1988) 37-67.

Pazhani Murugan R., Radhakrishnan M., Balagurunathan R. Bioactive sugar molecule from Streptomyces aureocirculatus (Y10) against MRSA, VRSA and ESBL pathogens. Journal of Pharmacy Research. 2010; 3(9): 2180-2181.

Radhakrishnan M., Balaji S., Balagurunathan R. Thermotolerant actinomycetes from the Himalayan mountain-antagonistic potential, characterization and identification of selected strains. Malaysian Applied Biology. 2007; 36 (1): 59-65.

Ravikumar S, Inbaneson S.J., Uthiraselvam M., Priya S.R., Ramu A., Banerjee M.B. Diversity of endophytic actinomycetes from Karangkadu mangrove ecosystem and its antibacterial potential against bacterial pathogens. J Pharm Res. 2011; 4(1): 294-296.

Sateesh V., Naikpatil Rathod J.L. Selective isolation and antimicrobial activity of rare actinomycetes from mangrove sediment of Karwar Journal of Ecobiotechnology. 2011; 3(10): 48-53.

Scherrer R., Gerhardt P. Molecular sieving by the B. megaterium cell wall and protoplast. J. Bacteriol. 1971: 107:718-735.

Selvameenal L., Radakrishnan M., Balagurunathan R. Antibiotic pigment from desert soil actinomycetes; biological activity, purification and chemical screening, Indian J Pharma Sci. 2009; 71: 499504.

Shirling E.B., Gottileb D. Methods for characterization of Streptomyces species. International Journal of Systematic Bacteriology. 1966; 16: 313- 340 .

Thenmozhi M., Krishnan K. Anti-Aspergillus activity of Streptomyces sp. VITSTK7 isolated from Bay of Bengal coast of Puducherry, India. J Nat Environ Sci. 2011; 2(2): 1-8. 
Ugawa Y., Sugawa K., Kudo K., Sugawara H., Tateno Y., Seino Y. Actinobase: An image database for identification of Actinomycetes. Trends in Actinomycetology (Japan). 1989; 17-20.

Valan arasu N., Duraipandiyan M., Agastian M., Ignacimuthu S. Characterization and phylogenetic analysis of novel polyene type antimicrobial metabolite producing actinomycetes from marine sediments: Bay of Bengal India. Mycol. Med. 2008; 18:147- 153.
Vimal V., Rajan B.M., Kannabiran K. Antimicrobial activity of marine actinomycete, Nocardiopsis sp. VITSVK 5 (FJ973467). Asian J Med Sci. 2009; 1(2): 57-63.

Yuan L., Zhang Y., Yu L., Sun C., Wei Y., Liu H., Li W., Zhang Y. Actinopolymorpha Cephalotaxi sp. nov., a novel actinomycete isolated from rhizosphere soil of the plant Cephalotaxus fortune, Int J Syst Evol Microbiol. 2010; 60: 51-54.

\section{How to cite this article:}

S. Silambarasan, E. Praveen kumar, T. Murugan, D. Saravanan and R. Balagurunathan. Antibacterial and antifungal activities of Actinobacteria isolated from Rathnagiri hills. J App Pharm Sci. 2012; 2 (10): 099-103. 